\title{
Design and Performance Analysis of Different Dielectric Substrate based Microstrip Patch Antenna for 5G Applications
}

\author{
Nurulazlina Ramli ${ }^{1}$, Shehab Khan Noor ${ }^{2 *}$, Taher Khalifa ${ }^{3}$ and N. H. Abd Rahman ${ }^{4}$ \\ Centre of Advanced Electrical and Electronic Systems (CAEES) ${ }^{1,2,3}$ \\ The Faculty of Engineering, Built Environment and Information Technology, SEGi University, Kota Damansara. \\ 47810 Petaling Jaya, Selangor, Malaysia \\ Antenna Research Centre (ARC), Faculty of Electrical Engineering, Universiti Teknologi MARA, Malaysia ${ }^{4}$
}

\begin{abstract}
In this paper, a $3.5 \mathrm{GHz}$ microstrip patch antenna using three different substrates materials with varying relative permittivity have been designed. However, the thickness of the substrates are slightly different from each other which is $1.6 \mathbf{~ m m}$ for FR-4, $1.575 \mathrm{~mm}$ for RT-5880 and $1.58 \mathrm{~mm}$ for TLC-30 have been chosen to carry out this work. The three substrates materials are FR-4 (Design-1), RT-5880 (Design-2), and TLC-30 (Design-3) with the relative permittivity of $4.3,2.2$, and 3 , respectively. The antennas' performances in terms of reflection coefficient, voltage standing wave ratio (VSWR), bandwidth, gain, and efficiency performance is simulated, analyzed and compared using CST Microwave studio (CST 2019). The findings reveal that there is a significant change in gain and bandwidth due to different relative permittivity and the thickness value of the substrate materials. The gains achieved were at $3.338 \mathrm{~dB}$, 4.660 dB, and 5.083 dB for Design-1, Design-2 and Design-3 respectively. The efficiency of the antennas also showed that TLC-30 gave the best efficiency at $75.70 \%$ when compared to FR-4 which was at $60.13 \%$ and RT-5880 which was at $61.51 \%$ efficiency. All the proposed antennas have a bandwidth above $100 \mathrm{MHz}$ where Design-1 had a bandwidth of $247.1 \mathrm{MHz}$ whilst Design-2 had a bandwidth of 129.7 MHz and finally, Design-3 had a bandwidth of $177.2 \mathrm{MHz}$.
\end{abstract}

Keywords-Efficiency; gain; microstrip patch antenna; permittivity; substrates

\section{INTRODUCTION}

Since the development of First Generation technology: 1G, Second Generation: 2G, Third Generation: 3G, Fourth Generation: 4G and finally, Fifth Generation: 5Gis being realized [1-2]. There have been significant and noteworthy improvements with every generation of communication systems. Fifth Generation (5G) technology is designed to offer alternatives to the limitations in the Fourth Generation (4G) technology. The limitations include limited bandwidth and speed. However, the benefits of $5 \mathrm{G}$ are shown in Fig. 1. In January 2020, the Malaysian Communications and Multimedia Commission (MCMC) established three bands, which are $700 \mathrm{MHz}, 3.5 \mathrm{GHz}$ and $26 / 28 \mathrm{GHz}$ for the implementation of the $5 \mathrm{G}$ in Malaysia [3]. The $3.5 \mathrm{GHz}$ frequency band is widely recognized and has been approved in most countries [4]. Accordingly, this research focuses on 3.5 $\mathrm{GHz}$ for the upcoming Fifth Generation (5G) applications.

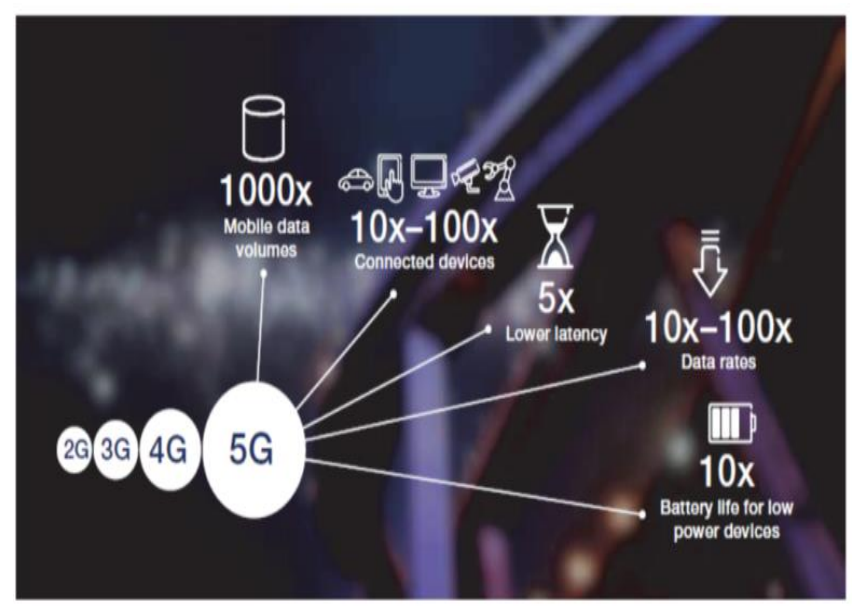

Fig 1. The Benefits of 5G in a Communication System [5].

Fifth Generation (5G) applications require a high-gain antenna to meet the demands of long-distance communications and this means higher data rates. This latest technology can be successfully implemented using a microstrip patch antenna. In general, an antenna is a radiating device developed for the transmission of electromagnetic waves [6]. The purpose of the microstrip patch antenna includes design convenience, low profile and is light weight. Microstrip patch antenna applications are used in a various industry such as medical, telecommunications and military systems. However, the narrow bandwidth and low gains are the greatest drawbacks of the microstrip patch antennas [7]. Nevertheless, the bandwidth can be increased using a thicker substrate which would increase the surface waves that move around the substrate and radiate the patch. As a result, the antenna gains reduce and this could affect the overall performance of the antenna. In addition, dimensions of the patch and feedline influences the performance of the antenna [8]. For microstrip patch antennas, the dielectric value ranges from 2 to 10 but this depends on the application for which the antenna has been designed for [9].

For this research, three microstrip patch antennas with three different dielectric substrates were designed and simulated to operate at $3.5 \mathrm{GHz}$ as part of a $5 \mathrm{G}$ application. The antennas were simulated using Computer Simulation

*Corresponding Author 
Technology (CST 2019) software which is widely recognized as user-friendly software [16] and the performance of the three antennas in terms of reflection coefficient, Voltage Standing Wave Ratio (VSWR), gains, bandwidth and efficiency was measured. The related works of FR-4, RT-5880 and TLC-30 substrate based antenna are discussed in Section II. The methodology and the design of the proposed antennas are discussed in Section III. The theoretical design of the antenna as well as the simulated design is discussed in Section IV. Section V focuses on the results obtained, the contrast of the proposed antennas and the discussion. The conclusion of this study is set out in Section VI.

\section{RELATED WORKS}

The two key factors that have to be considered when deciding on the antenna substrate are thickness and relative permittivity. These two factors play a vital role in influencing the performance of the antenna [10-15]. Several authors have previously used the FR-4 substrate to design the $3.5 \mathrm{GHz}$ patch antennas. Authors in [10-11] designed a microstrip patch antenna with a permittivity value of 4.4 and a thickness of $1.6 \mathrm{~mm}$. The antenna designed in [10] had achieved a gain of $3 \mathrm{~dB}$ and that the gain achieved in [11] was $2.24 \mathrm{~dB}$. With regards to the antenna bandwidth, the antenna designed in [10] had a bandwidth of $300 \mathrm{MHz}$ while the antenna in [11] had a bandwidth of $360 \mathrm{MHz}$. Based on [12-13], the authors have designed a rectangular patch antenna using RT-5880 as the substrate with a thickness $1.574 \mathrm{~mm}$ and $1.57 \mathrm{~mm}$ respectively. At $3.8 \mathrm{GHz}$, the bandwidth of the antenna was $72 \mathrm{MHz}$ [12] and the bandwidth was $50 \mathrm{MHz}$ [13] at $2.5 \mathrm{GHz}$. The gains achieved in [12] and [13] were $13.2 \mathrm{~dB}$ and $5.51 \mathrm{~dB}$ respectively. The authors in [14] and [15] have used TLC-30 as the dielectric substrate with a permittivity value of 3 to operate at $3.1 \mathrm{GHz}$ and $2.4 \mathrm{GHz}$ respectively. Nonetheless, the authors in [14] and [15] have used a substrate with a thickness of $1.575 \mathrm{~mm}$ and $1.5 \mathrm{~mm}$ respectively. In addition, the gains achieved were $2.9 \mathrm{~dB}$ and $2.7 \mathrm{~dB}$ respectively. However, the information related to bandwidth has not been mentioned in papers [14-15].

\section{Methodology}

This paper consists of three microstrip patch antennas using three different dielectric substrates. The specific substrate materials used are FR-4 for Design-1, RT-5880 for Design-2 and TLC-30 for Design-3. The overall objective of this project was achieved by following the steps shown in Fig. 2. The desired parameter is considered significant prior to pre-design, as it has a major impact on the overall performance of the antenna. The key concept was to design three antennas that would operate at $3.5 \mathrm{GHz}$. The antennas must have a reflection coefficient value (S11) of less than -10 $\mathrm{dB}$, a VSWR of less than or equal to $2 \mathrm{~dB}$, a line impedance match at $50 \mathrm{Ohms}$ and a bandwidth greater than or equal to $100 \mathrm{MHz}$ as shown in Table I below. In addition, series of optimization to achieve the desired results in terms of reflection coefficient and VSWR was conducted. Next, the gains and radiation patterns of the proposed antennas have been analyzed. Lastly, the simulated results of Design-1, Design-2 and Design-3 were compared.

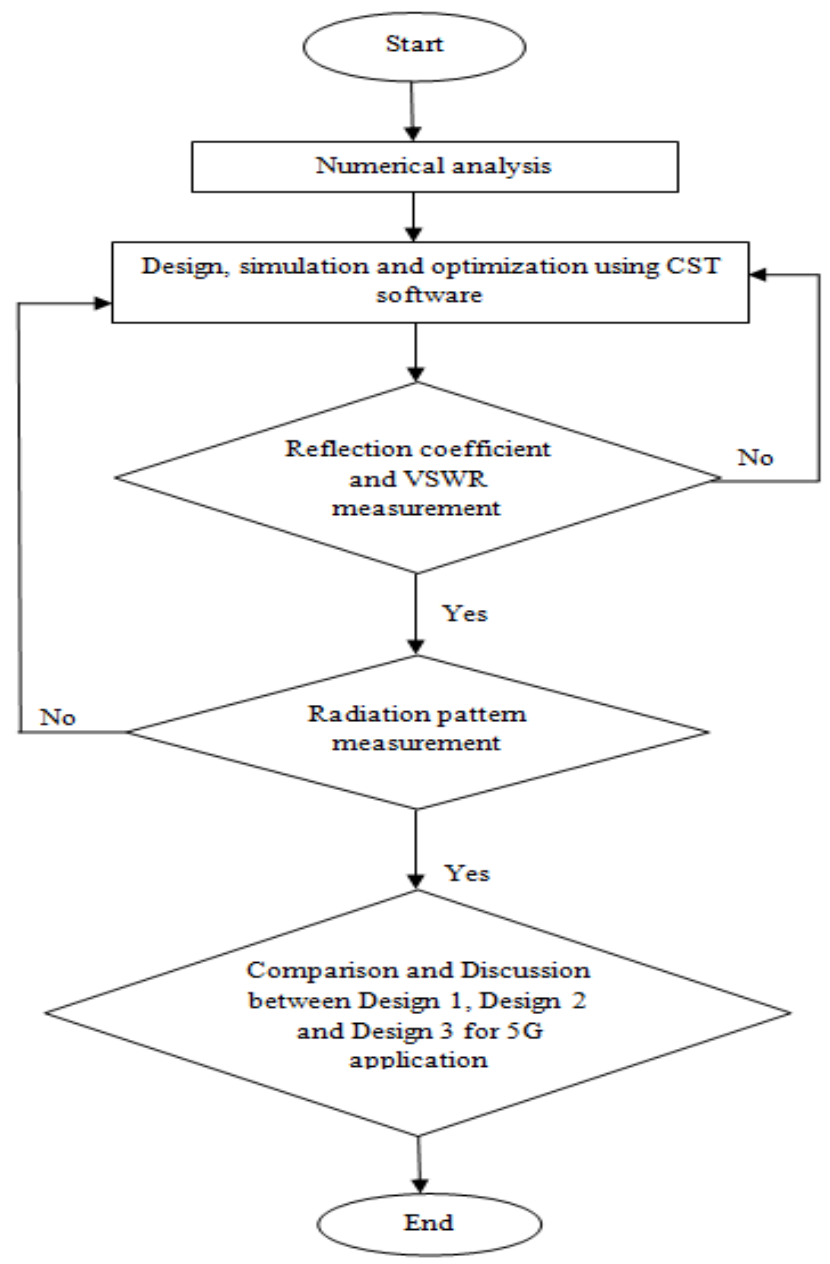

Fig 2. Flowchart for antenna Design-1, Design-2 and Design-3.

TABLE I. DESIGN SPECIFICATIONS OF THE ANTENNAS

\begin{tabular}{|l|l|}
\hline Specification & Values \\
\hline Frequency, $\mathrm{f}$ & $3.5 \mathrm{GHz}$ \\
\hline Reflection coefficient, S11 & Less than $-10 \mathrm{~dB}$ \\
\hline VSWR & $1: 2$ \\
\hline Input Impedance, $\mathrm{Z}$ & $50 \mathrm{Ohms}$ \\
\hline Copper thickness, $\mathrm{mm}$ & $0.035 \mathrm{~mm}$ \\
\hline Bandwidth & $\geq 100 \mathrm{MHz}$ \\
\hline
\end{tabular}

\section{ANTENNA Design}

A microstrip patch antenna consists of a radiating patch, a dielectric substrate and a ground plane. The patch is typically made of a conductive material such as copper or gold. Primarily, the substrate is required so as to give the antenna mechanical strength. The ground plane is a flat conductive material which acts as part of the antenna to reflect the radio waves emitted from the other components of the antenna. The basic structure of the microstrip patch antenna is illustrated in Fig. 3. The dimensions of the proposed antennas can be calculated using the formulas (1)-(9) shown below [17]. 


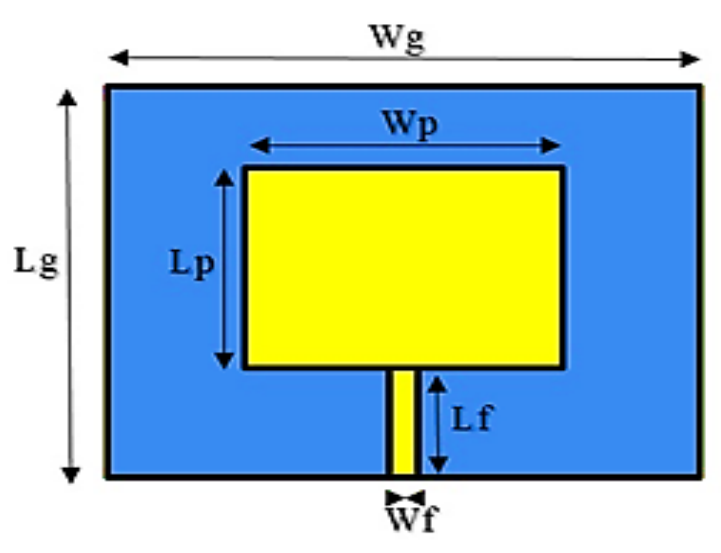

Fig 3. Basic Dimensions of Microstrip Patch Antenna [6].

The width, Wp and the length, Lp of the patch are calculated using the equations below:

$\mathrm{Wp}=\frac{\mathrm{c}}{2 \mathrm{fo} \sqrt{\frac{(\varepsilon r+1)}{2}}}$

Here $\mathrm{C}=3 \times 10^{8} \mathrm{~m} / \mathrm{s}$ (light speed), $\varepsilon \mathrm{r}=$ permittivity of substrate and $\mathrm{f}_{\mathrm{o}}=$ resonant frequency $(\mathrm{GHz})$

$\mathrm{Lp}=$ Lreff $-2 \Delta \mathrm{L}$

Where $\mathrm{L}_{\text {reff }}$ can be found using:

$\mathrm{L}_{\text {reff }}=\frac{c}{2 f o \sqrt{\varepsilon r e f f}}$

$\varepsilon r e f f=\frac{\varepsilon r+1}{2}+\frac{\varepsilon r-1}{2}\left[1+12 \frac{\mathrm{h}}{\mathrm{w}}\right]^{\frac{-1}{2}}$

Moreover, $\Delta \mathrm{L}$ can be found using:

$\Delta L=0.412 h\left(\frac{\varepsilon \mathrm{reff}+3}{\varepsilon \mathrm{reff}-0.258}\right)\left(\frac{\frac{w}{h+0.264}}{\frac{w}{h+0.813}}\right)$

The width $\mathrm{Wg}$ and length $\mathrm{Lg}$ of the ground plane can be found using:

$\mathrm{Wg}=6 \mathrm{~h}+\mathrm{Wp}$

$\mathrm{Lg}=6 \mathrm{~h}+\mathrm{Lp}$

here $\mathrm{h}=$ height of the substrate.

The width of feed line, Wf:

$\mathrm{Zo}=[87 / \sqrt{ }(\mathrm{Er}+1.141))] \ln (5.98 \mathrm{~h} / 0.8 \mathrm{Wf})$

The length of feedline, Lf:

$\mathrm{Lf}=\frac{\mathrm{Lg}-\mathrm{Lp}}{2}$

Design-1 used a flame retardant (FR-4) substrate. This dielectric substrate has a relative permittivity of 4.3 and with a thickness of $1.6 \mathrm{~mm}$. Design-2 used the Rogers (RT-5880) which offers a relative permittivity of 2.2 and a standard substrate thickness of $1.575 \mathrm{~mm}$. Design-3 is completed used Taconic (TLC-30) and has a relative permittivity of 3 and a thickness range of $0.51 \mathrm{~mm}$ to $6.35 \mathrm{~mm}$ [18]. However, for this research work, $1.58 \mathrm{~mm}$ was selected to ensure that all proposed antennas were of similar thickness for performance comparison purposes. Using the formulas (1) - (9) above, the dimensions of the three antennas were calculated. However, the numerical results were not achieved at $3.5 \mathrm{GHz}$. As a result, a series of optimizations were performed until the resonant frequency is $3.5 \mathrm{GHz}$ was achieved.

The length and width of the ground plane are indicated by "Lg" and "Wg" while the length and width of the patch are represented by "Lp" and "Wp" respectively. The width and length of the feedline are represented by "Wf" and "Lf" respectively. It has been observed that by increasing the patch width of "Wp" and the feedline length of "Lf" led to the achievement of the resonant frequency. In addition, the reduction of patch length " $\mathrm{Lp}$ " and feedline width "Wf" enabled Design-1 and Design-2 antennas to achieve resonant frequency. To recapitulate, an increase in the patch area and feedline area has resulted in the desired output being achieved. The calculated and optimized dimensions of the antennas are shown in Table II to Table IV. In addition, the front and back views of Design-1 to Design-3 are shown in Fig. 4.

\section{TABLE II. CALCULATED AND OPTIMIZED DIMENSION OF DESIGN-1}

Design-1 using FR-4 substrate

\begin{tabular}{|l|l|l|}
\hline Notation & Calculated Value (mm) & Optimized value (mm) \\
\hline Wp-1 & 26.31 & 33.5 \\
\hline Lp-1 & 20.20 & 19.35 \\
\hline Wg-1 & 35.91 & 36 \\
\hline Lg-1 & 29.8 & 29.8 \\
\hline Wf-1 & 3.175 & 3 \\
\hline Lf-1 & 4.8 & 6.00 \\
\hline
\end{tabular}

TABLE III. CALCULATED AND OPTIMIZED DiMENSION OF DESIGN-2

\begin{tabular}{|l|l|l|}
\hline \multicolumn{2}{|l|}{ Design-2 using RT-5880 substrate } \\
\hline Notation & Calculated Value (mm) & Optimized value (mm) \\
\hline Wp-2 & 35 & 46.45 \\
\hline Lp-2 & 26.4 & 27.6 \\
\hline Wg-2 & 36.908 & 47 \\
\hline Lg-2 & 31.698 & 31.698 \\
\hline Wf-2 & 4.8 & 4.46 \\
\hline Lf-2 & 1.4 & 1.9 \\
\hline
\end{tabular}

TABLE IV. CALCULATED AND OPTIMIZED DIMENSION OF DESIGN-3

\begin{tabular}{|l|l|l|}
\hline \multicolumn{2}{|l|}{ Design-3 using TLC-30 substrate } \\
\hline Notation & Calculated Value (mm) & Optimized value (mm) \\
\hline Wp-3 & 30.28 & 40 \\
\hline Lp-3 & 24.12 & 23.46 \\
\hline Wg-3 & 39.79 & 42 \\
\hline Lg-3 & 33.6 & 33.71 \\
\hline Wf-3 & 2.75 & 3.85 \\
\hline Lf-3 & 4.74 & 5.45 \\
\hline
\end{tabular}




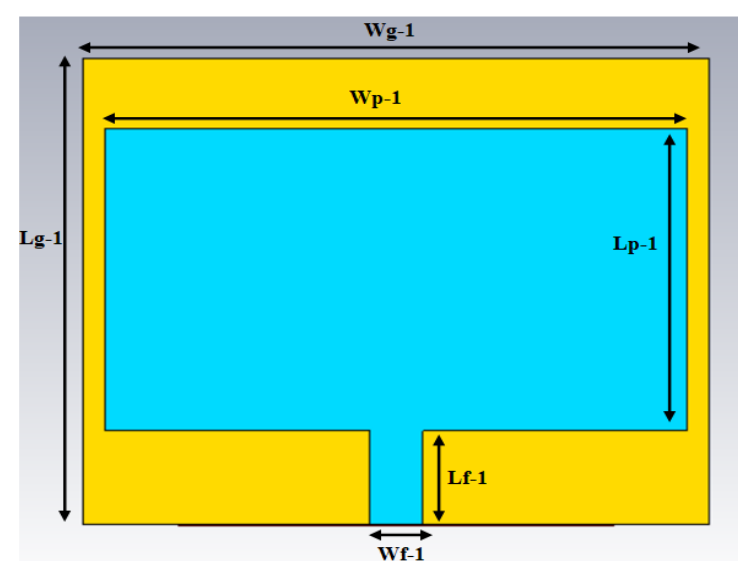

(a)

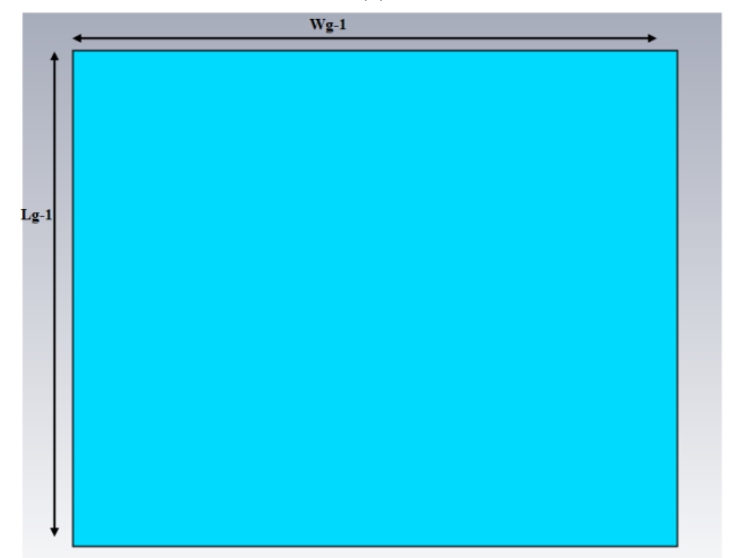

(b)

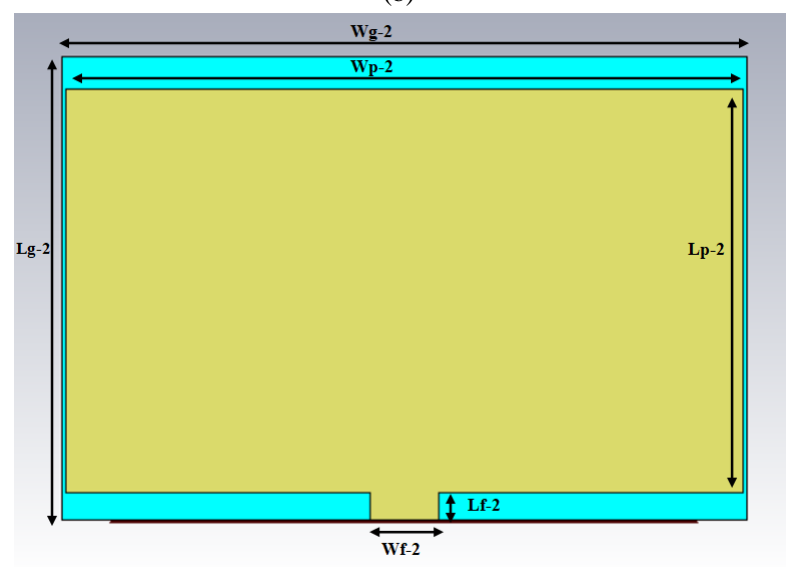

(c)

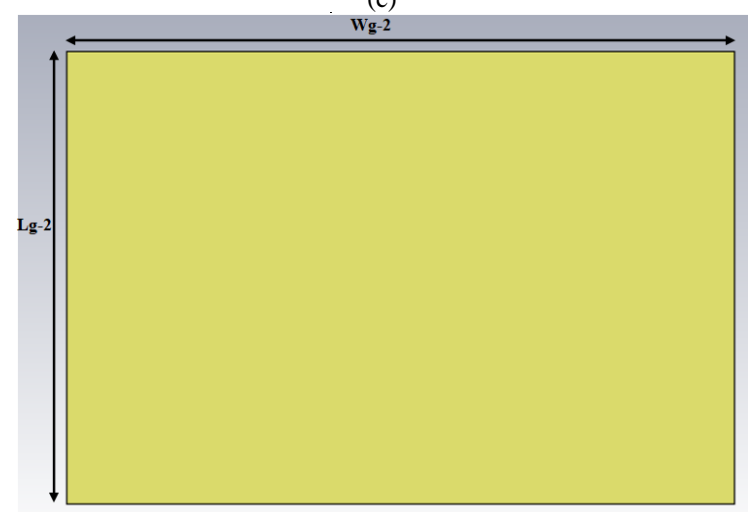

(d)

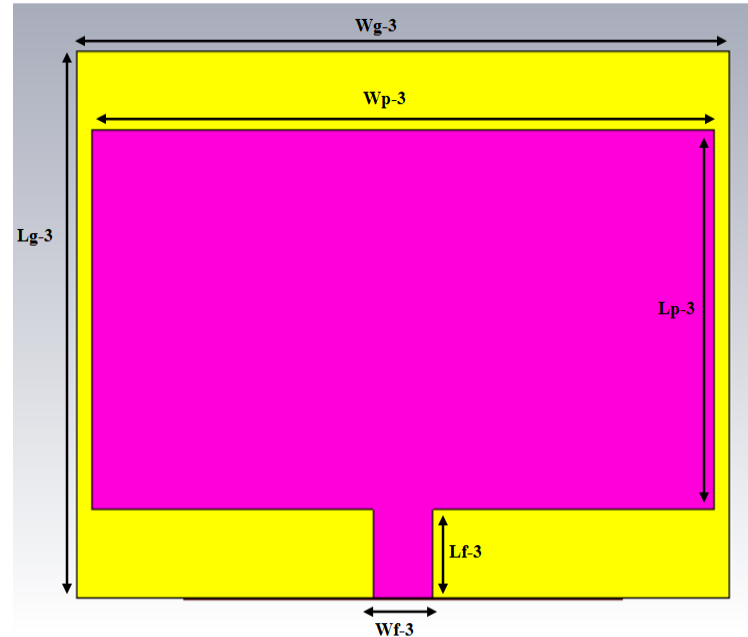

(e)

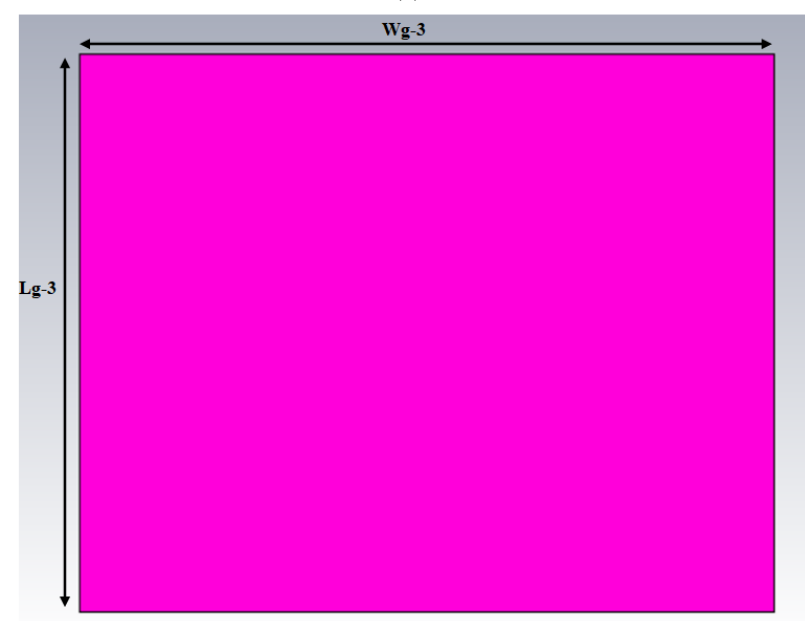

(f)

Fig 4. CST Simulated Design (a) Front View of Design -1 (b) Back View of Design-1 (c) Front View of Design -2 (d) Back View of Design-2 (e) Front View of Design-3 (f) Back View of Design-3.

\section{RESUlts AND DisCUSSION}

The simulated results for antennas Design-1, Design-2 and Design-3 were compared in terms performance and the results are discussed in the three sections below.

\section{A. Reflection Coefficient (S11) and VSWR}

Fig. 5 shows the coefficient of reflection, S11 for Design1, Design-2 and Design-3. Fig. 5 shows that Design-1 obtained S11 of $-28.48 \mathrm{~dB}$ while operating at $3.5 \mathrm{GHz}$. Subsequently, the antenna covered a bandwidth of $247.1 \mathrm{MHz}$ (3.3677 GHz-3.6147 GHz) at the desired frequency. Design-1 achieved good results in terms of S11 and bandwidth through the optimization process. Meanwhile, Design-2 achieved a lower S11 value of $-14.13 \mathrm{~dB}$ and with a lower bandwidth of $129.7 \mathrm{MHz}(3.4373 \mathrm{GHz}-3.567 \mathrm{GHz})$ while operating at the desired frequency. However, Design-3 achieved the best results when compared to Design-2 in terms of S11 and bandwidth. At $3.5 \mathrm{GHz}$, Design-3 achieved S11 value of $18.81 \mathrm{~dB}$ with a bandwidth of $177.2 \mathrm{MHz}(3.4085 \mathrm{GHz}-3.5857$ $\mathrm{GHz}$ ). Fig. 5 demonstrates antenna Design-1 had improved bandwidth performance followed by Design-3 and Design- 2 . 


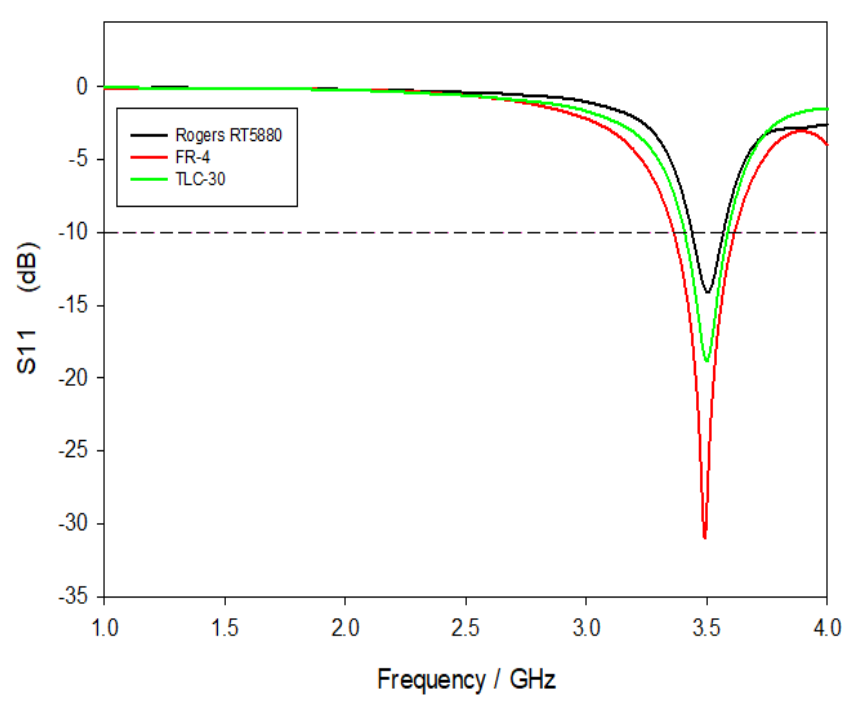

Fig 5. Reflection Coefficient of Design-1, Design-2 and Design-3.

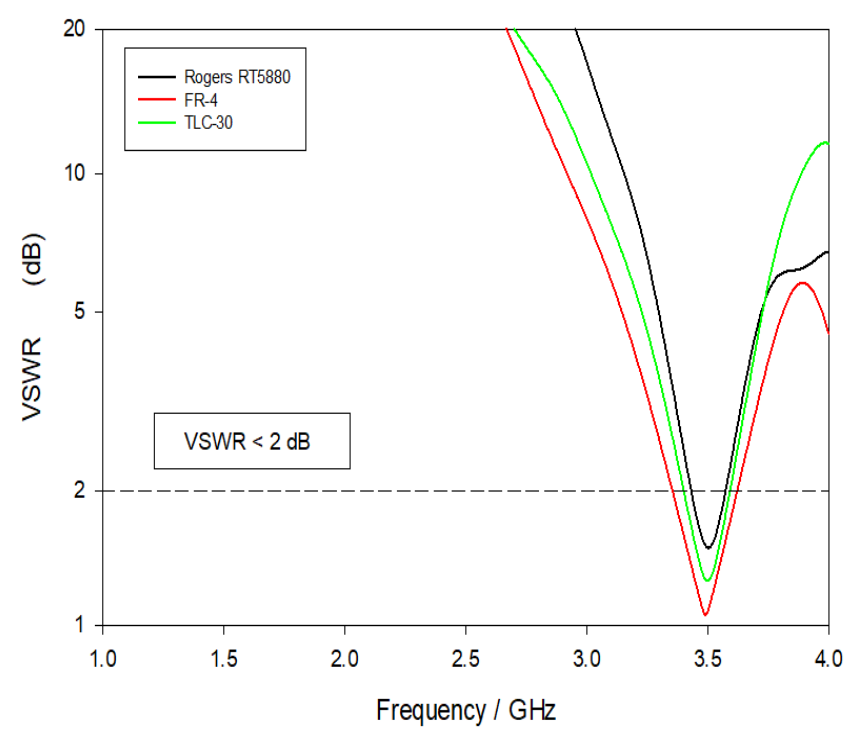

Fig 6. VSWR of Design-1, Design-2 and Design-3.

Fig. 6 shows the VSWR for Design-1, Design-2 and Design-3. According to the ITU standards for $5 \mathrm{G}$ mobile communication system application [19], all three of the proposed antennas are eligible for $5 \mathrm{G}$ applications as the VSWR is less than 2. The VSWR for Design-1, Design-2 and Design-3 were 1.078, 1.48 and 1.259, respectively.

\section{B. Radiation Pattern of the Proposed Antennas}

Further investigation was conducted in relation to the radiation pattern of the proposed antennas using CST software. In the design and analysis of the antenna, the radiation pattern is considered to be one of the major aspects since it has a direct influence on the performance of the antenna. Fig. 7 depicts the three dimensional (3D) view, together with the gains achieved by the proposed Design-1, Design-2 and Design-3 respectively. The maximum gain of $5.083 \mathrm{~dB}$ was achieved by Design-3 while operating at the desired frequency of $3.5 \mathrm{GHz}$. Subsequently, Design-1 and Design-2 achieved gains of $3.338 \mathrm{~dB}$ and $4.660 \mathrm{~dB}$ at the desired frequency respectively. In addition, the radiation pattern in the two dimensional (2D) view is shown in Fig. 8. All the three antennas have a reasonable linear directional behavior, which means that the antennas can cover long ranges in one particular direction.

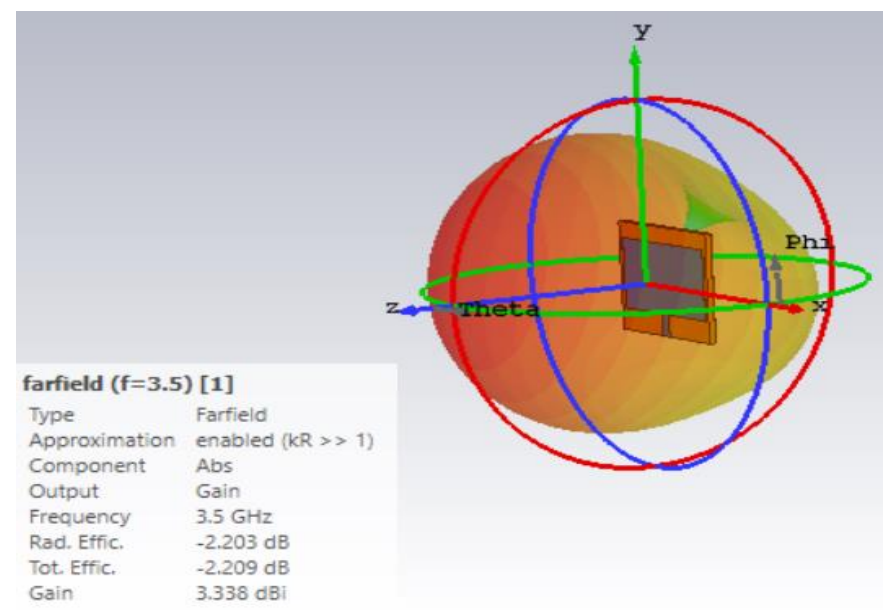

(a)

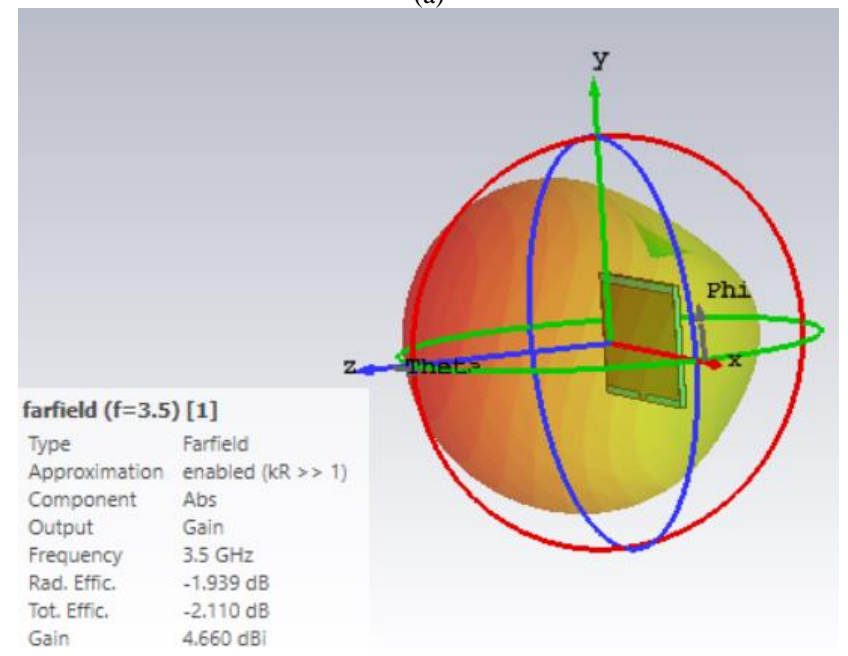

(b)

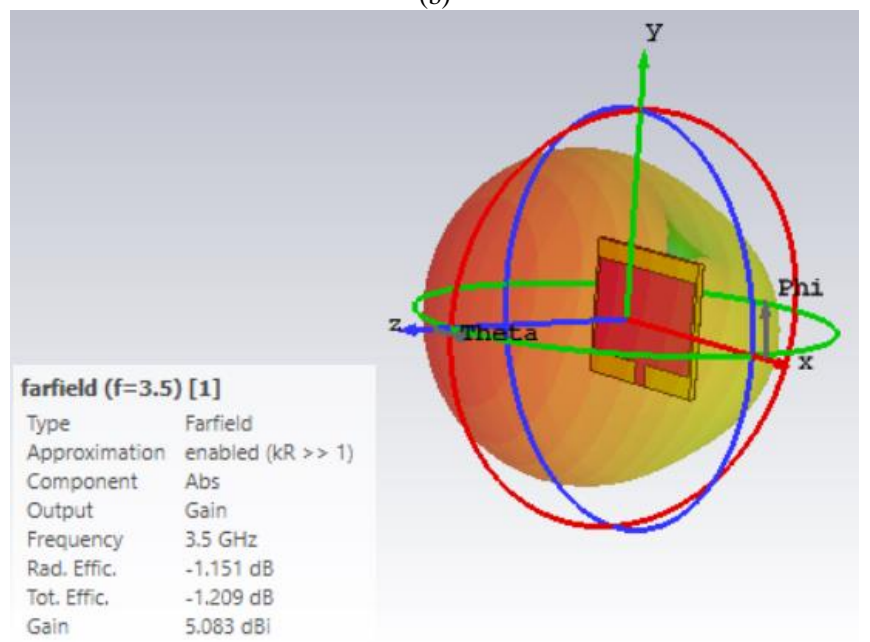

(c)

Fig 7. Three Dimensional (3D) view of the Radiation Pattern (a) Design-1 (b) Design-2 (c) Design-3. 


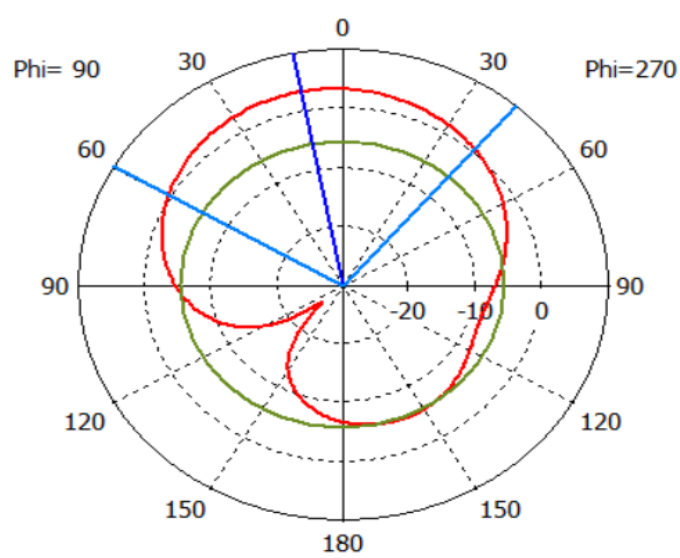

Theta / Degree vs. dBi

(a)

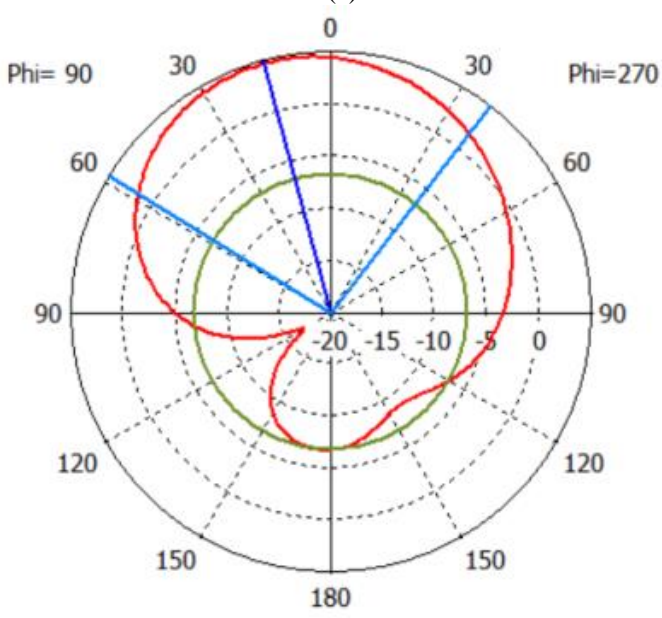

Theta / Degree vs. dBi (b)

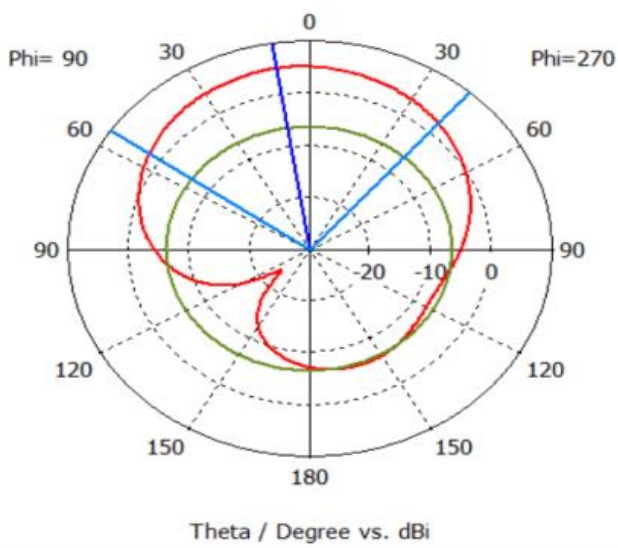

(c)

Fig 8. Two Dimensional (2D) view of the Polar Pattern (a) Design-1 (b) Design-2 (c) Design-3.

\section{Comparison of the Proposed Antenna Designs}

Table V shows the comparison of the three proposed antennas with other referenced antennas. It was noted that Design-3 had the best performance in terms of gain and bandwidth. Fifth Generation (5G) applications require higher gain and a larger bandwidth. It has been observed that Design3 had a sufficiently higher gain of $5.083 \mathrm{~dB}$ with a wider bandwidth of 177.2 MHz. Design-1 had a lower gain of 3.338 $\mathrm{dB}$ with a bandwidth of 247.1 MHz. Subsequently, Design-2 achieved a high gain of $4.660 \mathrm{~dB}$ with a narrower bandwidth of $129.7 \mathrm{MHz}$. It was noted that the thickness and relative permittivity of the substrate had a major influence on the performance of the antennas. It was observed that a substrate with a higher permittivity and a higher thickness value helped the antenna achieve a wider bandwidth with reduced gains.

TABLE V. COMPARISON OF THE PROPOSED ANTENNAS WITH REFERENCED ANTENNAS

\begin{tabular}{|l|l|l|l|l|l|l|l|}
\hline Reference & Dielectric substrate & $\begin{array}{l}\text { Frequency, } \\
\text { GHz }\end{array}$ & S11, dB & VSWR & Gain, dB & Bandwidth, MHz & Patch Area $(\mathbf{l} \times \mathbf{w}), \mathbf{~ m m}^{2}$ \\
\hline$[10]$ & FR-4 & 3.5 & -29.5 & 1 & 3 & 300 & 2500 \\
\hline$[11]$ & FR-4 & 3.5 & $<10$ & $\leq 2$ & 2.24 & 360 & 1140 \\
\hline Design-1 & FR-4 & 3.5 & -28.48 & 1.078 & 3.338 & 247.1 & 648.225 \\
\hline$[12]$ & RT-5880 & 3.8 & -18.2 & $\leq 2$ & 13.2 & 72 & 792.48 \\
\hline$[13]$ & RT-5880 & 2.5 & -12.105 & 1.4871 & 5.51 & 50 & 1571.92 \\
\hline Design-2 & RT-5880 & 3.5 & -14.13 & 1.48 & 4.660 & 129.7 & 1282.02 \\
\hline$[14]$ & TLC-30 & 3.1 & $<10$ & $\leq 2$ & 2.9 & - & 182 \\
\hline$[15]$ & TLC-30 & 2.4 & $<10$ & $\leq 2$ & 2.7 & - & 876 (rectangle + triangle) \\
\hline Design-3 & TLC-30 & 3.5 & -18.81 & 1.259 & 5.083 & 177.2 & 938.4 \\
\hline
\end{tabular}


Due to technological advancement, an antenna has to be small and be equipped with a wider bandwidth and higher gain. From the simulated results, it can be seen that Design-1 had a much smaller patch dimension of $648.225 \mathrm{~mm}^{2}$ compared to Design-2 with a dimension of $1282.02 \mathrm{~mm}^{2}$ and finally, Design-3 with a dimension of $938.4 \mathrm{~mm}^{2}$. This indicates that a smaller patch helped to achieve a wider bandwidth of 247.1 MHz. However, Design-3 achieved the highest gain of $5.08 \mathrm{~dB}$ compared to Design-1 gains $3.338 \mathrm{~dB}$ while Design-2 achieved gain of $4.660 \mathrm{~dB}$. Design-2 had a narrow bandwidth which was advantageous for cancelling unwanted signals and was capable of transferring maximum energy. From the comparisons above, the proposed antennas can be deployed for use in Fifth Generation (5G) applications as they had performed better in terms of bandwidth and gain.

\section{CONCLUSION}

The assessment of the results and the comparison between substrate materials FR-4, RT-5880 and TLC-30 has been extensively studied. The aim of the proposed antenna designs was to achieve good performance in terms of gain and bandwidth while maintaining a reflection coefficient below $10 \mathrm{~dB}$ and VSWR $\leq 2$. All the proposed antennas achieved good performance (higher gains and bandwidth $\geq 100 \mathrm{MHz}$ ) while meeting the reflection coefficient and VSWR requirements at $3.5 \mathrm{GHz}$. Moreover, Design-1, Design-2 and Design-3 have an efficiency of $60.13 \%, 61.51 \%$ and $75.70 \%$ at the desired frequency. This indicated that TLC-30 would be the best choice for $5 \mathrm{G}$ applications among the three proposed antennas. Further studies would need to be carried out to improve the efficiency of the proposed antennas, in particular to improve the gains and bandwidth while having a smaller antenna dimension.

\section{ACKNOWLEDGMENT}

The authors would like to take this opportunity to express their gratitude to the Faculty of Engineering, Built Environment \& Information Technology (FoEBEIT), SEGi University, Kota Damansara for supporting this research work.

\section{REFERENCES}

[1] Zhang H, Dong Y, Cheng J, Hossain MJ, Leung VCM, "Fronthauling for 5G LTE-U ultra dense cloud smallcell networks," IEEE Wireless Commun. 2016. vol. 23(6), pp 48-53.

[2] S. Path, "A Straight Path Towards 5G," Straight Path Communications Inc, 2015, pp. 1-29.

[3] "Allocation of spectrum bands for mobilebroadband service in Malaysia," Malaysian Communications and Multimedia Commission, January 2020, pp 1-2.
[4] "Roadmap for C-band spectrum in ASEAN," GSMA, August 2019, pp 35-37.

[5] Olga Boric-Lubecke, Victor M. Lubecke, Branka Jokanovic, Aditya Singh, Ehsaneh Shahhaidar, and Bryson Padasdao, "Microwave and Wearable Technologies for 5G", 12th International Conference on Telecommunication in Modern Satellite, Cable and Broadcasting Services (TELSIKS), 14-17 October 2015.

[6] K. W. S. Al Kharusi, N. Ramli, S. Khan, M. T. Ali and M. H. Abdul Halim, "Gain Enhancement of Rectangular Microstrip Patch Antenna using Air Gap at $2.4 \mathrm{GHz}$," International Journal of Nanoelectronics and Materials Volume 13 (Special Issue), pp 211-224 (2020).

[7] Rajveer S Yaduvanshi, Harish Parthasarathy and Asok De, "MagnetoHydrodynamic Antenna Design and Development Analysis with prototype," International Journal of Advanced Computer Science and Applications (IJACSA), Vol. 2, No.2, February 2011.

[8] Nagapushpa K.P and Chitra Kiran N, "Studying Applicability Feasibility of OFDM in Upcoming 5G Network," International Journal of Advanced Computer Science and Applications (IJACSA), Vol. 8, No. 1, 2017.

[9] Zain Ul Abedin and Zahid Ullah, "Design of a Microstrip Patch Antenna with High Bandwidth and High Gain for UWB and Different Wireless Applications," (IJACSA) International Journal of Advanced Computer Science and Applications, Vol. 8, No. 10, 2017.

[10] Archana R.Cheekatla and Pankaj S. Ashtankar, "Compact micro strip antenna for $5 \mathrm{~g}$ mobile phone applications," International Journal of Applied Engineering Research. vol 14(2), pp.108-111, 2019.

[11] J. Ashish and A. P. Rao, "Design and Implementation of Compact Dual band U-slot Microstrip Antenna for 2.4GHz WLAN and $3.5 \mathrm{GHz}$ WiMAX Applications,” 2019 International Conference on Smart Systems and Inventive Technology (ICSSIT), Tirunelveli, India. pp. 1084-1086.

[12] H. Sajjad, W. T. Sethi, K. Zeb and A. Mairaj, "Microstrip patch antenna array at $3.8 \mathrm{GHz}$ for WiMax and UAV applications," 2014 International Workshop on Antenna Technology: Small Antennas, Novel EM Structures and Materials, and Applications (iWAT), Sydney, NSW. pp. 107110.

[13] Jahariah Sampe, Noor Hidayah Mohd Yunus, Jumril Yunas, Alipah Pawi and Zeti Akma Rhazali, "Design and fabrication of a dual band 1.8/2.5 GHZ antenna for RF energy harvester" International Journal of Engineering \& Technology. Vol. 7(4).

[14] K. Thana Pakkiam and J. S. Mandeep, "Design of multiband parallel strip patch antenna for DCS/WLAN/WIMAX and RFID applications," 2016 IEEE Industrial Electronics and Applications Conference (IEACon), Kota Kinabalu, 2016, pp. 348-353.

[15] K. T. Pakkiam, J. S. Mandeep and M. T. Islam, "Design of microstrip antenna for modern wireless communication," International Symposium on Telecommunication Technologies, Kuala Lumpur, 2012, pp. 42-46.

[16] H. Yon , N. H. Abd Rahman, M. A Aris and H. Jumaat, "Developed high gain microstrip antenna like microphone structure for $5 \mathrm{G}$ application," International Journal of Electrical and Computer Engineering (IJECE) Vol. 10, No. 3, June 2020, pp. 3086-3094.

[17] C. A. Balanis, "Antenna theory: a review," Proc. IEEE, vol. 80, no. 1,1992, pp. 7-23.

[18] "TLC" datasheet published by TACONIC, www.taconic-add.com ( accessed on 25.05.2020)

[19] D. Andreev, "Overview of ITU-T activities on 5G/IMT-2020," Int. Telecommun. Union, 2017. 